\title{
Targeted therapy for non-small-cell lung cancer
}

\author{
${ }^{1} \mathrm{KI}$ Rasul, ${ }^{2} \mathrm{AM}$ Al-Khater \\ ${ }^{1,2}$ Senior Consultant Oncologist, Department of Haematology \& Oncology, Al Amal Hospital, Doha, Qatar
}

AUTHORS Mok TS, Wu Y-L, Thongprasert S et al.

Correspondence to KI Rasul,

TITLE Gefitinib or carboplatin-paclitaxel in pulmonary adenocarcinoma

JOURNAL N Engl J Med 2009; 361:947-57. doi:I0.1056/NEJMoa08I0699

DECLARATION OF INTERESTS No conflict of interests declared.

\author{
Al Amal Hospital, Hamad Medical \\ Corporation, P.O. Box 3050, \\ Doha, Qatar
}

tel. +974 439785 I

e-mail krasul@hmc.org.qa

\section{SUMMARY}

Lung cancer is the most common cause of cancer mortality worldwide for both men and women, causing approximately I.2 million deaths per year.' Adenocarcinoma is the most common type of lung cancer, constituting nearly $40 \%$ of cases. Platinum-based combination chemotherapy, such as carboplatinpaclitaxel, is a standard first-line therapy for advanced non-small-cell lung cancer (NSCLC).

First-line Iressa versus Carboplatin/Paclitaxel in Asia (Iressa Pan-Asia Study [IPASS]) was a phase three multicentre, randomised, open-label, parallel-group study comparing gefitinib (an oral inhibitor of epidermal growth factor receptor [EGFR]; Iressa, AstraZeneca) with carboplatin (Paraplatin, Bristol-Myers Squibb) plus paclitaxel (Taxol, Bristol-Myers Squibb) as first-line treatment in clinically selected patients in East Asia who had advanced NSCLC. The primary endpoint was progression-free survival. Secondary endpoints included overall survival, the objective response rate, quality of life, reduction in symptoms, safety and the adverse-event profile. Evaluations of efficacy according to the baseline mutation status of the EGFR gene were planned exploratory objectives.

The study results showed that median survival was longer for patients receiving gefitinib (18.6 months) compared with patients receiving carboplatin-paclitaxel (I7.3 months). More patients in the gefitinib group experienced an improvement in their quality of life compared with the chemotherapy group, as demonstrated on the Functional Assessment of Cancer Therapy-Lung (FACT-L) questionnaire and by scores on the Trial Outcome Index (TOI) (odds ratio, I.78; 95\% Cl, I.402.26; $\mathrm{p}<0.001)$.

\section{OPINION}

There are specific EGFR-activating mutations that correlate with tumour response to the tyrosine kinase inhibitor gefitinib. ${ }^{2-4}$ EGFR gene mutations are associated with histopathological subtype of NSCLC (adenocarcinoma), ethnicity and non-smoking history. In this selected study population, the EGFR gene mutation was much higher compared with other studies with unselected populations (59.7 vs 12.1 and $27 \%$ ). ${ }^{3,4}$ This suggests that the prevalence of EGFR mutation is higher in the Asian population than in Western populations.

This study shows that first-line therapy with gefitinib as compared with conventional cytotoxic chemotherapy in patients with EGFR mutations improves progression-free survival, objective response rates and quality of life. This is also confirmed in the West Japan Thoracic Oncology Group trial, which showed increased progression-free survival for gefitinib compared with cisplatin plus docetaxel in patients with EGFR mutations..$^{5}$ This presents a paradigm shift in the treatment of pulmonary adenocarcinoma and hopefully will pave the way for future advances in personalised treatments for lung cancer.

\section{REFERENCES}

I Parkin DM, Bray F, Ferlay J et al. Global cancer statistics, 2002. CA Cancer J Clin 2005; 55:74-108. doi:I0.3322/canjclin.55.2.74

2 Lynch TJ, Bell DW, Sordella R et al. Activating mutations in the epidermal growth factor receptor underlying responsiveness of non-small-cell lung cancer to gefitinib. N Engl J Med 2004; 350:2 129-39. doi:10.1056/NEJMoa040938

3 Hirsch FR, Varella-Garcia M, Bunn PA et al. Molecular predictors of outcome with gefitinib in a phase III placebo-controlled study in advanced non-small-cell lung cancer.J Clin Oncol 2006; 24:503442. doi: I0.1200/JCO.2006.06.3958
4 Tamura K, Okamoto I, Kashii T et al. Multicentre prospective phase II trial of gefitinib for advanced non-small-cell lung cancer with epidermal growth factor receptor mutations: results of the West Japan Thoracic Oncology Group trial (WJTOG0403). Br J Cancer 2008; 98:907-14. doi:10.1038/sj.bjc.6604249

5 Mitsudomi T, Morita S, Yatabe Y et al. Gefitinib versus cisplatin plus docetaxel in patients with non-small-cell lung cancer harbouring mutations of the epidermal growth factor receptor (WJTOG3405): an open label, randomised phase 3 trial. Lancet Oncol 2010; II:I2I-8. doi:10.1016/SI470-2045(09)70364-X 